\section{EMBRYRIDDLE}

Aeronautical University

SCHOLARLY COMMONS
Journal of Aviation/Aerospace

Education \& Research

Volume 9

Number 2 JAAER Winter 2000

Article 1

Winter 2000

\title{
A Comparison of the Effectiveness of PC-Based Aviation Training Devices and Conventional Flight Training Devices for Instrument Flight Training
}

Wendy S. Beckman

Follow this and additional works at: https://commons.erau.edu/jaaer

\section{Scholarly Commons Citation}

Beckman, W. S. (2000). A Comparison of the Effectiveness of PC-Based Aviation Training Devices and Conventional Flight Training Devices for Instrument Flight Training. Journal of Aviation/Aerospace Education \& Research, 9(2). https://doi.org/10.15394/jaaer.2000.1244

This Article is brought to you for free and open access by the Journals at Scholarly Commons. It has been accepted for inclusion in Journal of Aviation/Aerospace Education \& Research by an authorized administrator of Scholarly Commons. For more information, please contact commons@erau.edu. 


\title{
A COMPARISON OF THE EFFECTIVENESS OF PC-BASED AVIATION TRAINING DEVICES AND CONVENTIONAL FLIGHT TRAINING DEVICES FOR INSTRUMENT FLIGHT TRAINING
}

\author{
Wendy S. Beckman
}

\begin{abstract}
Since the time instrument flight became common, ground training devices have been used to teach students basic instrument flight skills. The skills which students learn in these ground trainers are then transferred to an aircraft during later stages of training. There are three types of ground training devices that are recognized by the Federal Aviation Administration for flight training purposes. The first type of device is called a "simulator," which is a device "that exactly duplicates the performance and physical aspects of a specific airplane" (Butcher, 1996). Simulators are multi-million dollar machines, which are mounted on hydraulic legs and have full visual displays. These machines are so realistic that it is possible for a pilot to be trained to certificate completion in such a device, with no time in an actual aircraft. The use of these devices is typically limited to airline use, due to both their initial and operating costs.
\end{abstract}

The next type of recognized device is a "flight training device" (FTD). Although there are seven levels of FTDs, such devices generally replicate an aircraft cockpit and often have a basic visual display system. However, FTDs do not have to replicate the pressures on the flight controls that are experienced in flight nor provide an exact imitation of each switch or knob found in a specific airplane (Butcher). FTDs are currently in use in the majority of the leading university flight training programs, as well as at smaller flight schools nationwide. The FAA has indirectly acknowledged the value of these devices for over two decades, by allowing FTD training to partially fill the requirements for obtaining an instrument rating.

In the last several years, a third ground training device, the personal computer aviation training device (PCATD) has become available to flight students and their instructors. These devices typically consist of a generic aircraft control console which provides the flight controls necessary for performing flight maneuvers, as well as a visual display on a PC monitor, which consists of the typical flight instruments seen in an aircraft. The FAA has recently recognized PCATDs as a viable method of obtaining instrument flight training, although there has been little research into their effectiveness for such training.

The cost of most currently manufactured FTDs is prohibitive to many flight schools, especially smaller schools, since a typical FTD can cost upwards of $\$ 80,000$ (Pope, 1997). However, a PCATD can offer a much lower cost alternative, typically $\$ 5,000$ to $\$ 8,000$ (Pope, 1997). There are several advantages to teaching some aspects of instrument skills on the ground instead of in flight, so it seems especially important to determine if PCATDs can be used effectively in instrument training. Since "traditional approaches to training on actual equipment are becoming more and more prohibitive because of relatively high cost and their limited ability to be used for training on unusual or potentially catastrophic situations" (Su, 1984), the use of PCATDs may prove to be a viable alternative to using actual aircraft for many flight schools. PCATDs, if proven to be effective, may also provide a lower cost alternative for the larger flight schools which currently use FTDs.

\section{Statement of the Problem}

The FAA has recently approved the use of PCATDs to satisfy a portion of the training requirements for an instrument rating, although little study of the effectiveness of these devices has been done. The purpose of this study is to compare the effectiveness of a PCATD to that of a conventional FTD in providing positive transfer of learning of specific instrument skills to an aircraft.

\section{Research Questions}

The research hypothesis for this study was that the Jeppesen FS-200 PCATD and the Fraca 141 FTD would not prove to be equally effective in preparing a student to perform the specific instrument flight skill of executing holding patterns in an aircraft. The null hypothesis was that there would be no significant difference between the scores received on an evaluation of holding pattern skills of students receiving training on a FTD and students receiving training on a 
PCATD. The null hypothesis was tested by using a post-test only control group experimental design.

\section{Review of Related Literature}

Overview

Ground training devices have a long history of use in the aviation industry. From the early days of Link trainers to the present day multi-million dollar flight simulators used by air carriers, the ability of such devices to provide cost effective and safe training in various phases of instrument flight have been recognized.

\section{Transfer of Training Theory}

Given that ground training devices are widely thought to provide the benefits listed above, the question of the actual effectiveness of such devices is raised. The issue of ground trainer effectiveness is essentially an issue of transfer of training effectiveness, since the objective of using a ground trainer is to positively transfer skills from the trainer to an aircraft. Skill transfer occurs when an individual is able to perform a task more easily as a result of having previously practiced a different task (Lintern, 1992).

\section{Methods of Measuring Transfer or Training}

Transfer of training effects are usually measured in one of two ways: 1) savings measure, and 2) first shot measure (Hammerton 1967). The savings measure determines the reduction of the training efforts required in the actual piece of equipment to reach a predetermined level of performance. The first-shot measure evaluates the performance of the trainee on their first trial after transferring to the real piece of equipment. The appropriate measure to use depends on the purpose of the study (Hammerton, 1967).

Roscoe (1971) and Roscoe and Williges (1980) pointed out that the savings measure method of evaluating effectiveness fails to consider the amount of practice in the flight training device in determining the training effectiveness of the device. Since the FAA allows direct substitution of hours from a FTD, i.e., 15 out of 40 hours of required instrument flight training can be in an FTD instead of an aircraft, using the first shot method to measure what a student has gained by practicing in a ground trainer is the most relevant method of analysis. Essentially, the first shot measure answers the question: "given a certain amount of learning with the simulator, how much of it will be retained on first transferring to the real situation?" (Hammerton, 1967).

Fidelity

The issue of ground trainer fidelity is an old one, and is particularly relevant to this study, since the difference between a FTD and a PCATD is largely a matter of fidelity. Fidelity refers to the degree to which a device or a facility accurately simulates a machine or system ( $\mathrm{Su}, 1984)$. Generally speaking, the higher the fidelity level of a device, the higher the cost of the device. The fidelity of simulators has often been thought to be a determining factor in the amount of transfer effectiveness derived. However, one must keep in mind that training effectiveness is the main concern. If high fidelity does not lead to high transfer of training, then concern over simulator fidelity is overstated. Rouse (1981) pointed out that the key issue in the use of simulators is the level of fidelity necessary to assure transfer of training from simulators to real equipment.

A relationship between fidelity and transfer was first proposed by R.B. Miller in 1954. In this model, an increase in the degree of simulator fidelity is accompanied by increases in both transfer of training and cost effectiveness. Although this model has been cited widely (Fink and Shriver 1978, Kinkade and Wheaton 1972, Hays 1981), there has been little empirical evidence of this relationship.

In fact, many other researchers have found that comparable training results may be obtained with both low and high fidelity simulators of the same equipment (Duncan and Shepherd 1975, Crawford and Crawford 1978, Johnson 1981). In a study by Martin and Waag (1978), it was shown that flight simulators with higher fidelity provided too much information for novice trainees and actually detracted from simulator effectiveness. Prophet (1966) reported a study that compared a low fidelity simulator (an inexpensive photographic mock-up of a cockpit) with that of an elaborate trainer. No significant difference between groups was found.

Kinkade and Wheaton (1972) proposed a relationship between the degree of simulator fidelity, types of simulator fidelity, and the stages of learning. Early in a training program, when a student is learning procedures, the trainee is not able to benefit from a high degree of either physical or environmental fidelity. However, as skill is acquired (familiarization training), there are requirements for increased physical and environmental fidelity. During the last stages of training (skill training), Kincade and Wheaton found increases in both types of fidelity are beneficial.

Thomson (1989) also found that the relationship between degree of fidelity and amount of transfer is not always clear. He indicated that the research he reviewed was not always comparable with respect to such factors as levels of instructor 
ability, instructional techniques, types of simulators, student time on trainers, flight experience of subjects, and measuring techniques. Fidelity and transfer relationships vary as a function of the many factors listed above, which are external to a training device. Generally, Thomson found that if familiarization is the training objective, relatively low levels of fidelity are adequate, whereas if complex or complete training on a high level task is required, high level fidelity of simulation is required.

In summary, no consensus has been reached on the relationship between fidelity and other factors such as cost, training, and stage of learning. The research in this area is not very conclusive. The difficulty of measuring various types of fidelity seems to be part of the reason for the inconclusive results. However, most of the more recent studies seem to indicate that high fidelity does not necessarily equate to high training transfer.

\section{PCATD Studies}

There were only two published studies found which attempted to evaluate the effectiveness of PCATDs. Oritz (1993) conducted a study which used a PCATD to provide initial training for student pilots. This study found there was a positive transfer of learning from the device to an aircraft. However, the study did not compare the effectiveness of a PCATD to that of a FTD. Since the FAA currently accepts FTD training as a substitute for flight training, it seems important to establish the effectiveness of a PCATD in comparison to these devices. In addition, the study only involved visual flight maneuvers. Since FTDs have historically been viewed as important only in learning instrument flight skills,(flight training credit is not allowed for FTD usage in visual flight maneuvers, while it is for instrument training) it seems appropriate to assess the effectiveness of PCATDs in the instrument training environment.

A second study on the effectiveness of PCATDs was done at the University of Illinois during the 1994-1995 academic year (Taylor, Lintern, Hulin, Talleur, Emanuel, Phillips, 1997). The study evaluated a PCATD in a transfer of training experiment to evaluate its ability to assist in instrument flight training. The researchers found that the level of savings in airplane flight time varied from negative $25 \%$ to positive $40 \%$, depending on the particular tasks involved. However, in general, the transfer savings were positive and substantial, particularly when new maneuvers were being introduced. The study concluded that PCATDs are effective training devices for some tasks and generate savings in those areas, while they do not provide assistance in training in other areas. For example, the introductory lessons for steep turns, intersection holds, ILS approaches, VOR approaches, NDB approaches, and DME arcs all had savings levels of positive $17 \%$ to positive $39 \%$. However, the final review lessons on the same maneuvers resulted in savings levels from negative $13 \%$ to positve $17 \%$.

\section{METHODOLOGY}

\section{Subjects}

The study population consisted of those students in the Parks College Part 141 training program who were enrolled in basic attitude instrument training during the Fall 1996, Spring 1997, or Summer 1997 semesters. Thirty-two students comprised this population. These students were randomly assigned to either the PCATD group or the FTD group. The PCATD group received holding pattern instruction in the PCATD prior to demonstrating their skills in an aircraft, and the FTD group received instruction in the FTD prior to demonstrating their skills in an aircraft.

The only inclusion criteria for the study was that the student was enrolled in basic attitude instrument flight training, between two specified flight lessons, when they participated in the study. This was necessary so that each student brought the same previous flight experience to the study. The only exclusion criteria is that students who had access to, or have previously used, a PC-based flight simulator were asked to self report this fact and would have been excluded from the study. This was necessary so the results were not be skewed by individuals who had practiced on a PC-based device in the past, or who might be tempted to practice during the study. However, no students reported such access to PC-based devices, and so no students had to be excluded.

\section{Procedure}

This study was conducted using a post-test only control group experimental design. Each subject received a 45 minute group lecture on how to execute a holding pattern. This lecture included such information as the definition of a holding pattern, what a holding pattern looks like, holding pattern entries, how to fly the holding pattern, and how to correct for wind while flying the holding pattern. A handout packet was distributed for use during the lecture, and for the student to refer to when they began training in the FTD or PCATD. Within two weeks from the time of the lecture, each subject 
received two, one hour sessions of flight instruction on holding patterns in either the FTD or the PCATD (whichever they were randomly assigned to). A very specific profile was flown with each student to minimize variability. The first ground trainer lesson involved familiarization with flying the device, navigation aid radial interception, and execution of two holding patterns. The second session consisted of the execution of three holding patterns. One instructor was used to conduct all of the training in order to minimize variability.

After receiving training in the FTD or PCATD, each student then executed a holding pattern in an aircraft for evaluation. The flight was approximately 20 minutes in length, and consisted of two times around a specified holding pattern. The two ground training device sessions and the aircraft session were conducted in less than a two week time period so recency of experience factors were minimized.

The following parameters were measured during the student evaluation flight in a TB-9 aircraft: Altitude, heading, ability to track assigned radial, time inbound to the station, orientation during the holding pattern, and ability to become established in the hold. Two complete circuits of a direct entry holding pattern were evaluated. To reduce variability, each student was evaluated by the same person, a Part 141 Assistant Chief Flight Instructor at Parks College.

A student's score was calculated based on the following criteria:

Students began with 100 points. Any of the following deviations resulted in the score being lowered:

Altitude off more than $100 \mathrm{ft}$ - minus 1 point for each 3 seconds of deviation

Heading off more than 10 degrees while outbound minus 1 point for each 3 seconds of deviation

More than 10 degrees from assigned radial while inbound - minus 1 point for every 3 seconds of deviation

Time inbound - minus 1 point for every five seconds deviation from one minute

Orientation - minus 5 points for each incorrect answer regarding orientation during holding pattern

Inability to become established in hold - minus 10 points for each unsuccessful circuit

\section{RESULTS}

The score resulting from each student's evaluation flight in a TB-9 aircraft can be seen in Table 1.

Table 1: Raw Data Scores from TB-9 Flights

Training Done in FTD

\begin{tabular}{ll} 
Subject \# & Score \\
\hline 1 & 68 \\
2 & 100 \\
3 & 93 \\
4 & 53 \\
5 & 55 \\
6 & 73 \\
7 & 42 \\
8 & 68 \\
9 & 77 \\
10 & 35 \\
11 & 65 \\
12 & 87 \\
13 & 89 \\
14 & 61 \\
15 & 83 \\
16 & 41
\end{tabular}

Training Done in PCATD

\begin{tabular}{ll} 
Subject \# & Score \\
\hline 1 & 58 \\
2 & 57 \\
3 & 38 \\
4 & 68 \\
5 & 87 \\
6 & 98 \\
7 & 67 \\
8 & 87 \\
9 & 76 \\
10 & 91 \\
11 & 59 \\
12 & 49 \\
13 & 84 \\
14 & 66 \\
15 & 70 \\
16 & 73
\end{tabular}

As can be seen from the table, the scores for students receiving training in a FTD varied from a low 35 to a high of 100. The scores for students receiving training in a PCATD varied from a low of 38 to a high of 98 . 
After it was determined that the data was approximately normally distributed, both descriptive and inferential statistics were calculated for the two data sets. Table 2 provides a listing of these statistics. The subject scores in Table 2 are listed in ascending order for ease of computation. The average score for the subjects who received training in a FTD was 68.125 , while the average score for the subjects who received training in a PCATD was 70.5. The standard deviation for the FTD group was 19.54, while the standard deviation for the PCATD group was 16.26 .

\section{TABLE 2 - STATISTICS FOR FTD AND PCATD DATA SETS}

Training in FTD

SUBJECT SCORE SQUARE SUBJECT SCORE SQUARE

$\begin{array}{llllll}1 & 35 & 1225 & 1 & 38 & 1444\end{array}$

$\begin{array}{llllll}2 & 41 & 1681 & 2 & 49 & 2401\end{array}$

$\begin{array}{llllll}3 & 42 & 1764 & 3 & 57 & 3249\end{array}$

$\begin{array}{llllll}4 & 53 & 2809 & 4 & 58 & 3364\end{array}$

$\begin{array}{llllll}5 & 55 & 3025 & 5 & 59 & 3481\end{array}$

$\begin{array}{llllll}6 & 61 & 3721 & 6 & 66 & 4356\end{array}$

$\begin{array}{llllll}7 & 65 & 4225 & 7 & 67 & 4489\end{array}$

$\begin{array}{lllllll}8 & 68 & 4624 & 8 & 68 & 4624\end{array}$

$\begin{array}{llllll}9 & 68 & 4624 & 9 & 70 & 4900\end{array}$

$\begin{array}{llllll}10 & 73 & 5329 & 10 & 73 & 5329\end{array}$

$\begin{array}{llllll}11 & 77 & 5929 & 11 & 76 & 5776\end{array}$

$\begin{array}{llllll}12 & 83 & 6889 & 12 & 84 & 7056\end{array}$

$\begin{array}{lllllll}13 & 87 & 7569 & 13 & 87 & 7569\end{array}$

$\begin{array}{lllllll}14 & 89 & 7921 & 14 & 87 & 7569\end{array}$

$\begin{array}{llllll}15 & 93 & 8649 & 15 & 91 & 8281\end{array}$

$\begin{array}{llllll}16 & 100 & 10000 & 16 & 98 & 9604\end{array}$

$\begin{array}{lllc}\text { SUM } 1090 & 79984 & \text { SUM } 1128 & 83492 \\ & & & \\ \text { AVG } 68.125 & & \text { AVG } & 70.5 \\ \text { STD DEV 19.54 } & \text { STD DEV } & 16.26\end{array}$

A two-tailed t-test was performed on the data. The value of $t$ was calculated to be .3737 . At an alpha of .10 and with 30 degrees of freedom, the $p$ value from the "Distribution of $t$ Table" was found to be 1.697 . Since the calculated value of $t$ was less than the $t$ Table $p$ value, the null hypothesis was not rejected. This means that the difference between the means of the two groups is not statistically significant. This result supports the null hypothesis, which was that the two devices are equally effective in preparing a student for this task.

\section{DISCUSSION}

\section{Summary}

In this study, two randomly selected groups of instrument flight students at Parks College of St. Louis University were evaluated on their ability to perform holding patterns in a TB-9 aircraft after receiving training in either a Jeppesen FS-200 PCATD or a Frasca 141 FTD. The results of the study indicate that there was no significant difference between the scores of the two groups. This supports the conclusion that the two devices are comparable in their ability to prepare students to perform holding patterns in a TB-9 aircraft.

This finding supports the results of the only other study done to date which investigated the effectiveness of PCATDs for instrument training. In the University of Illinois study of 1994-1995 (Taylor, Lintern, Hulin, Talleur, Emanuel, Phillips, 1997) PCATDs were found to generally have positive skill transfer capabilities, particularly when new instrument flight maneuvers were being introduced to students. Although FTDs were not used for comparison purposes in the University of Illinois study, that study also supports the conclusion that PCATDs are effective devices in teaching basic instrument skills such as holding patterns.

\section{Limitations of the Study}

A major limitation of the study was the population selected for study. Since the population selected represented college flight students, the results may not be applicable to a more general population of flight students. It can be argued that college students are typically younger and more comfortable with computer technology (such as that used in PCATDs) than a typical flight student. Because the majority of flight students nationally are not concurrently enrolled in a college program, this lack of applicability does pose a problem. Therefore, the findings from this study should be viewed as preliminary data. The findings of this study support the conclusion that PCATDs are as effective as FTDs in preparing students for performing holding patterns, however, further studies encompassing a greater variety of subjects are warranted.

Another limitation of the study is the sample size. Although all of the students enrolled in the Parks College Flight II course during the 1996-1997 academic year were utilized, the sample size was only $n=32$, which resulted in a sample size of only $n=16$ per group. Some authorities 
argue that $n=30$ subjects per group is a minimum for experimental studies; others argue that studies with tight controls can be valid with $n=15$ subjects per group (Gay, 1992). From a practical standpoint, trying to conduct the study over a period longer than one year in order to increase the sample size seemed to introduce unacceptable causes of variability (i.e., the same flight instructor would not be available to instruct all of the students). In addition, as stated above, the results of this study should be used as preliminary findings. Since there has been such a limited number of studies conducted on the effectiveness of PCATDs, simply being able to suggest that future studies are warranted is of value at this stage.

Another limitation of the study was the controlled nature of the study. Many factors beyond the training device itself can impact the effectiveness of the training experience. These include 'instructors' roles, user acceptance, management support, student characteristics, simulator fidelity, training strategy, training time and pre-training knowledge" (Su, 1984). Controlling for these variables was largely accomplished in this study and was necessary for appropriate conduct of the study. However, it also limited the ability to extrapolate from the students used for this study to the general flight student population. All of the subjects were Parks College students, taught by a Parks College instructor, using the Parks College flight training syllabus, etc. It is certainly not clear that the results obtained in this study are indicative of what would be experienced elsewhere in the flight student population.

One variable which was not controlled was a student's history of experience with either PC-based or arcade-type games. While the subjects were questioned regarding their prior or current experience with PCATDs, their more generic computer game experience was not addressed. It is possible that the level of comfort of a student with computer games impacts their ability to effectively integrate skills taught on a PCATD.

An additional limitation of the study is that holding patterns are only one very specific task that is required during instrument flight. Although executing a holding pattern does encompass other instrument skills such as basic aircraft control and navigation, it is still a fairly narrow portion of instrument flight. Therefore, although PCATDs appear to be as effective as FTDs in providing skill transfer in this maneuver, future study of other tasks is required.
A final limitation of this study is that it compared the effectiveness of a specific PCATD (the Jeppesen FS-200), to the effectiveness of a specific FTD (the Frasca 141). Each of these devices is a very commonly used representative of their class of device, but the results of this study are not necessarily applicable to other manufacturers' devices. Although the terms "PCATD" and "FTD" are generic, the equipment used in this study were specific. It is reasonable to suppose that results similar to those found in this study would be experienced on other equipment types, but by no means are they guaranteed. Once again, additional study is necessary to verify the applicability.

\section{Conclusions}

Although PCATDs are being widely produced and purchased by both flight students working towards an instrument rating and by pilots who have already obtained the rating and simply desire to maintain their skills, there has been very little research into the effectiveness of the devices. In fact, only two published studies regarding PCATDs were found in the literature review, and the findings from these studies, while positive towards the PCATD, were certainly not conclusive. The purpose of this study was to add more data to the small amount that currently exists.

If PCATDs can be shown to be as effective in providing positive transfer of training as FTDs are, the benefit to the flight training community is sizable. PCATDs are a more accessible and affordable means of providing ground based instrument flight instruction than are FTDs. Many flight schools which cannot afford an FTD would easily be able to fund the purchase of a PCATD for their students. In addition, some students would probably choose to assemble their own PCATD, especially if they already owned the necessary PC platform. This would result in even greater accessibility, as well as provide the opportunity for home practice. If PCATDs are effective devices, flight schools will be able to take advantage of ground training devices in much larger numbers than ever before. Because many emergency scenarios cannot be safely practiced in an aircraft, the widespread integration of such devices in flight training should enhance the safety of future instrument pilots.

\section{Recommendations for Future Research}

As stated above, more extensive study of the effectiveness of PCATDs needs to be undertaken before any broad conclusions regarding their utilization in 
instrument flight training curriculums can be forumulated. The evaluation of the effectiveness of PCATDs in preparing students to perform instrument flight maneuvers beyond holding patterns (such as basic attitude flight, instrument navigation, and instrument approaches) would be the first step necessary in determining the usefulness of the devices throughout instrument flight training. The testing of both a larger and more varied pool of subjects than was available for this study is also required in order to establish the effectiveness of PCATDs. Finally, the evaluation of various types of PCATDs (beyond the Jeppesen FS-200 used in this study) is required before general statements regarding the entire class of devices known as PCATDs can be made.

Wendy S. Beckman earned an Ed.D. in Higher Education Administration from Saint Louis University, a M.S. in Engineering Management from the University of Missouri, and a B.S. degree in Industrial Engineering from North Carolina State University. She is an Associate Professor in the Department of Aviation Science at Parks College of Engineering and Aviation at Saint Louis University. 


\section{REFERENCES}

Baum, D.R. (1981). A framework and topics for empirical research on training simulator effectiveness. Proceedings of the ARI Sponsored Workshop for Behavioral and Social Sciences. Technical Report 547.

Butcher, R. (1996). PC's for IFR training. Flight Training, $10,46$.

Crawford, A.M., \& Crawford K.S. (1990). Simulation of operational equipment with a computer-based instructional system: A low cost training technology. Human Factors, 20, 123-128.

Duncan, K.D., \& Shepherd, A. (1975). A simulator and training technique for diagnosing plant failures from control panels. Ergonomics, 18, 627-641.

Fink, C.D., \& Shriver, E.L. (1978). Simulators for maintenance training: Some issues, problems, and areas for future research. (Technical Report AFHRL-TR-78-27). Lowry AFB, CO: Technical Training Division.

Finley, D.L., Rheinlander, F.W., Thompson, E.A., \& Sullivan D.J. (1972). Training effectiveness evaluation of naval training devices. Part I: A study of a carrier air traffic control center training device. (Technical Report No.

NAVTRAEQUIPCEN 70-C-0258-1). Washington, DC: US Navy.

Gagne, R.M. (1948). The measurement of transfer of training. Psychological Bulletin, 45, 97-130. Macmillan.

Gay, L.R. (1992). Educational research competencies for analysis and application. Englewood Cliffs, NJ:

Hammerton, M. (1967). Measures for the efficiency of simulators as training devices. Ergonomics, 10, 63-65.

Hays, R.T (1981). Research issues in the determination of simulator fidelity. Proceedings of the ARI Sponsored Workshop, US ARI for Behavioral and Social Sciences, Technical Report No. 547.

Johnson, S.L. (1981). Effect of training devices on retention and transfer of a procedural task. Human Factors, 23. 257-272.

Kinkade, R.G. \& Wheaton, G.R. (1972). Training device design. In P. Van Cott \& R.G. Kinkade (Eds.), Human Engineering Guide to Equipment Design, Washington DC: ARI.

Lahey, G.F., \& Edwards, B.J. (1986). The use of a part-task air intercept trainer in F-16 aircrew training: research results. Proceedings of the Interservice/Industry Training Equipment Conference, USA, 560-564.

Lintern, G. (1992). Flight simulation for the study of skill transfer. Simulation/Games for Learning. 22. 336-350.

Martin, E.L. \& Waag, W.L, (1978). Contributions of platform motion to simulator effectiveness: Study 1-basic contact (USAF Internal Report AFHRL-TR-78-15). Washington, DC: USAF.

Meister, D., Sullivan D.J., Thompson, E.A., \& Finley, D.L. (1971). Training effectiveness evaluation of naval training devices part II: A Study of device 2F66A (S-2E) trainer effectiveness (Technical Report NAVTRADEVCEN 69-C0322-2). Orlando, FL: US Navy.

Micheli, G.S. (1972). Analysis of the transfer of training, substitution, and fidelity of simulation training equipment (Report 2, Training Analysis and Evaluation Group). Orlando, FL: US Navy.

Miller, R.B. (1954). Psychological consideration in the design of training equipment, (Report WADC-TR-54-563, Wright Air Development Center). Wright-Patterson AFB, OH: USAF.

Murdock, B.B.J. (1957). Transfer designs and formulas. Psychological Bulletin, 54, 49-57.

Ortiz, G.A. (1993). Transfer of learning effectiveness: PC-based flight simulation. The Journal of Aviation/Aerospace Education and Research, 3, 29-33.

Osgood, C.E. (1947). The similarity paradox in human learning: A resolution. Psychological Review, 56, 132-143.

Pope, S. (1997, September 1). Desktop simulators come of age. Aviation International News, 98-99.

Prophet, W.W. \& Boyd, H.A. (1970). Device-task fidelity and transfer of training aircraft cockpit procedure

training. (Technical Report 70-10). Alexandria, VA: Human Resources Research Office.

Roscoe, S.N. (1971). Incremental transfer effectiveness. Human Factors, 13, 561-567.

Roscoe, S.N. \& Williges, B.H. (1980). Measurement of transfer of training. In S.N. Roscoe(Ed.) Aviation

Psychology (pp. 182-193). Ames, IA: The Iowa State University Press. 
Rouse, W.B. (1982). A Mixed-fidelity approach to technical training. Journal of Educational Technology Systems, $11,23-28$

Rouse, W.B. (1981). Experimental studies and mathematical models of human problem solving performance in fault diagnosis tasks. In P.R. Rasmussen, \& W.B. Rouse (Eds.) Human Detection and Diagnosis of System Failures (pp. 189-203). Newark, NJ: Plenum.

Ryan L.E., Puig, J.A., Micheli, G.S., \& Clarke, J.A. (1972). An evaluation of the training effectiveness of device 2F90. TA-4J operational flight trainer part I: The B Stage (Technical Report for NAVTRAEQUIPCEN). Orlando, FL: US Navy.

Sitterly, T.E. (1974). Degradation of learned skills: Static practice effectiveness for visual approach and landing (Technical Report D180-1786-1). Seattle, WA: The Boeing Company.

Sitterly, T.E. \& Berge, W.A. (1972). Degradation of learned skills: Effectiveness of practice methods on simulated space flight skill retention (Technical Report D180-15081-1). Seattle, WA: The Boeing Company.

Su, D.L. (1984). A review of the literature on training simulators: Transfer of training and simulator fidelity (Report No. 84-1). Atlanta, GA: Georgia Institute of Technology.

Taylor H.L., Lintern G., Hulin C.L., Talleur D., Emanuel T., \& Phillips S. (1997). Transfer of training effectiveness of personal computer-based aviation training devices (Report No. DOT/FAA/AM-97/11). Washington, DC: Government Printing Office.

Thomson, D.R. (1989). Transfer of training from simulators to operational equipment - Are simulators effective? Journal of Educational Technology Systems, 17, 213-218.

Valverde, H.H. (1973). A review of flight simulator transfer of training studies. Human Factors, 23, 510-514. 
https://commons.erau.edu/jaaer/vol9/iss2/1 